\title{
CONSUMER PERCEPTION TOWARDS TELEHEALTH IN THE AGE OF COVID-19
}

\author{
ROHAN RAJEEV ${ }^{1} \&$ DR. SANJAY PAWAR ${ }^{2}$ \\ ${ }^{1}$ Student, MBA, College: Symbiosis Institute of Management Studies, India \\ ${ }^{2}$ Associate Professor, College- Symbiosis Institute of Management Studies, India
}

\begin{abstract}
The telehealth industry has been around for a long time but it still the idea of receiving consultation virtually hasn't been very widely accepted by the masses. A lot of reasons have contributed to an aversion towards telehealth, a sense of discomfort, fear of breach of privacy or just the sheer satisfaction once received from in-person consultation that Telehealth couldn't promise to better. However, the Covid-19 pandemic has forced the masses to stay indoors. The lockdown temporarily restricted the liberty of visiting family physicians and doctors for minor and mild medical fatalities and encouraged them to receive consultation virtually. The study has been focused on the Indian consumer perception with respect to the city of Mumbai, which has been one of the worst affected cities in India due to the pandemic. Based on the data collected, a quantitative research was done with statistical analysis. The research gaps that have been aimed to fill are pertaining to the evolving trend of acceptance of Telehealth among the subjects of my study and the satisfaction sought post consuming telehealth services. The research can be of use to marketing researchers as well as medical professionals.

KEYWORDS: Telehealth, Consultation, Medical, Satisfaction, Perception
\end{abstract}

Received: Jun 08, 2020; Accepted: Jun 28, 2020; Published: Aug 19, 2020; Paper Id.: IJMPERDJUN2020815

\section{INTRODUCTION}

Telehealth is the use of technology and telecommunication for the distribution of health related services and information. From patients receiving consultation to doctors being able to participate in surgeries from miles away, Telehealth has certainly been recognised as the future in medical science. (World Health Organisation, 2016)

Telehealth first showed it's prominence in the 1950s. The invention of the radio in the 1900s paved way for this. A Canadian doctor used the telephone line to send radiology pictures in and around Montreal. Soon, it led to the exchange of information in the form of high definition images, reports and even motion pictures. (Bashshur \& Shannon, 2009)

With the boom in technology and communication, Telehealth stands at a point of revolution, where medical students can attend lectures, doctors can participate in surgeries, and patients can receive consultation, all just a click away on their devices.

However, despite showing signs of emergence in the 1950s, Telehealth didn't see the growth and potential market with respect to the consultation front. Patients worldwide preferred meeting the doctor in person to receive consultation. It could be sense of discomfort, fear of breach of privacy or just the sheer satisfaction once received from in-person consultation that Telehealth couldn't promise to better. (The Economic Times, 2020)(Wijesooriya, Mishra, Brand, \& Rubin, 2020)(Moeckli, Cram, Cunningham, \& Reisinger, 2013) (Wade, Karnon, \& Elshaug, 2010) 
The Covid-19 pandemic forced the world into a state of lockdown. This demanded a much needed digital revolution to take place in various industries. The pandemic proved to be a catalyst and gave the necessary push to existing industries and forced them to adapt to technology. The increasing necessity of staying 'socially-distant', brought the world together, virtually. (The Economic Times, 2020) (Bestsennyy, Gilbert, Harris, \& J, 2020)

It was once believed that it was the mostly the IT industry that could afford the luxury of working from home, however the pandemic has changed that perception. It has forced other industries to adapt to a digital model for the sake of survival. These months of the lockdown saw Banks, Schools, Colleges, Consultants, Government Bodies, Media houses and even Medical staff 'work from home'. The sheer precaution that had to be taken to avoid contraction of the virus stressed on the importance of virtual connectivity. (Bestsennyy, Gilbert, Harris, \& J, 2020) (The Economic Times, 2020) (Ganapathy, 2020)

Workers in the medical front were highly susceptible to this virus. The fact that Covid-19 patients could be symptomatic or asymptomatic put doctors and general physicians at great risk when they interacted with their patients. It demanded them to be socially distant from their patients to curb the spread. This compelled doctors to connect with their patients virtually using phone calls and video calls. The growing acceptance and use of platforms like FaceTime, WhatsApp Video call, Zoom, Hangouts proved to be a comfortable and convenient platform for doctors to communicate, assess and consult their patients while, not risking their or the patient's safety with respect to the virus. (Maese, Seminara, Shah, \& Szerszen, 2020) (The Economic Times, 2020)The Pandemic has surely increased the use and acceptance of Telehealth, but is this shift temporary or one that is here to stay?

A study conducted in the US states that the adaptation of Telehealth skyrocketed from $11 \%$ in 2019 , to $46 \%$ due to the pandemic and the lockdown cancelling health visits. In a survey conducted, the results proved that $76 \%$ respondents were highly or moderately likely to use telehealth going forward, and $74 \%$ of the consumers reported high satisfaction (Bestsennyy, Gilbert, Harris, \& J, 2020). This study has been a key factor in generating interest in this subject, and inspired me to conduct a similar study with respect to Mumbai, India to study the consumer perception towards telehealth and the impact of Covid-19 on the same. The research aims to focus on both the perspective to gain a clearer approach on the scope and viability of the industry.

\section{LITERATURE REVIEW}

Telehealth uses telecommunication to provide medical services to remote patients and facilitates exchange of information between physicians and specialists. (Bashshur R. , 1997)

It is said that it is the physician's vision that serves as the primary medium of perception to arrive at a diagnosis (Sinha, 2000). The adaption of telecommunication has always been one considered one with tremendous promise and potential because of the advantages it possesses, such as 1) Cost cutting in health care, 2) Shortened duration of visits, 3) Convergence of ICT \& Healthcare, 4) It also helps medicine students and young professionals get access to practices and knowledge, through experiential learning and courses at a fraction of the price. (Sinha, 2000) (The Economist, 1997) (Escobar, 1994)

A study conducted in USA in the year 2012 showed that if patients could have an 'acute' hospital at home with basic medical equipment, they could easily adapt to telehealth. This would save them $19 \%$ expenses. All it required was just to reach the patient and their carers how to give basic medication and injection, and this saw a fall in re-admission 
from $13.6 \%$ to $9 \%$ just over a span of 6 months(Roehr, 2012). Despite always being an industry that was recognised as 'high-potential', it didn't grow at the expected rate, or didn't see it being adapted at the expected scale. Many factors such as comfort of the patients, legal regulations pertaining to telemedicine, Privacy of data, Regulatory platforms, the view of medicine as a high-tech business and not just a healing industry have contributed to this stunted growth. (The Economic Times, 2020) (Wijesooriya, Mishra, Brand, \& Rubin, 2020) (Sinha, 2000) (Mair \& Whitten, 2000). Early researches have shown promise, but a lot of questions still remain unanswered and pose as a major issues that need to be addressed before telehealth could take off completely. Is telehealth suitable for initial consultation, or is it one that can be only used for follow up consultations? What are the effects of this mode on doctor-patient relationships? How communicative issues effect the delivery of the service? (Allen \& Perednia, 1995)(Brecht, Gray, Peterson, \& Youngblood, 1997)(Mair \& Whitten, 2000)(Ho, Karlinsky, \& S, 2004)(Bagchi, 2006) (Thaker, Monypenny, Olver, \& Sabesan, 2013) (Dick, Filler, \& Pavan, 1999)

The Covid-19 pandemic put the medical fraternity under tremendous strain. With the worldwide implementation of Social Distancing norms, face to face consultation has to be replaced by virtual consultation.(Gilbert, Billany, \& Adam R, 2020)(Bestsennyy, Gilbert, Harris, \& J, 2020) (Hollander \& Carr, 2020). The shift to Telehealth has also been widely accepted by the medical fraternity and patients as well. Telehealth has reduced the exposure of both doctors and patients, and has proved pivotal in reducing the risk of contraction of Covid-19. Telehealth has also helped patients receive personalised care from their clinicians, and has also given doctors suffering from mild symptoms to cater to their patients. (Wijesooriya, Mishra, Brand, \& Rubin, 2020)(The Economic Times, 2020) (Chellaiyan, Nirupama, \& Taneja, 2019)(Ateriya, Saraf, Meshram, \& Setia, 2018)

Teleconsultation has been offered by doctors in India since 2000, however there hasn't been much clarity regarding its legality. In fact, certain State Medical Councils, like the Karnataka State Medical Council had banned its doctors from providing teleconsultation and imposed serious consequences if they were caught practicing the same. The Government of India has now prescribed guidelines to be followed while practising telehealth. On March 25, 2020, The Board of Governors set up by the Health Ministry to regulate the practice of modern medicine published an amendment to the Indian Medical Council Regulations, 2002. According to that, a medicine practitioner registered under Indian Medical Council Act, 1956 and being enrolled in the State Medical Register could practice telehealth following the published guidelines. It is now perfectly legal for a medicine practitioner (MBBS \& above) to practice telehealth abiding by the prescribed guidelines. The doctors will have to display their registration number in all communication exchanged with the patients such as emails, prescriptions, fee receipts etc. As a thumb rule, prescribing drugs and medicine for first time use for chronic diseases should be avoided over phone call and a video call consultation is recommended, unless the patient is going for a refill for the same condition with a prescription not more than 6 months old. Prescriptions, fee receipts etc, need to carry the registration number of the doctor and a scanned copy of the same can be sent to the patient via email, message, WhatsApp etc. It is now completely legal for doctors to practice telehealth and they can provide consultation to patients remotely for a fee and they must maintain the same standard of care as done during in-person consultation. (Medical Council of India, 2020) (Ganapathy, 2020)

The Insurance Regulatory and Development Authority of India (IRDAI) has allowed insurers to cover telemedicine charges wherever regular medical consultation is allowed. This brings relief to policy holders as they can now avail their medical consultation telephonically while abiding by the safety norms of the pandemic (The Economic Times, 
2020). This also proved to be very beneficial for the doctors. A study conducted in the United States surveyed a local County Medical society and found out that prior to the pandemic, around $15 \%$ of them were offering telehealth facilities, whereas, after the onset of the pandemic, $89 \%$ of the members started offering telehealth services (Maese, Seminara, Shah, $\&$ Szerszen, 2020). A survey of the Medical Society Physicians showed that $90 \%$ of the professionals saw a decrease in their working hours, as patients were not coming in, a majority of them saw a fall in their weekly working hours by as much as 12 hours. (Maese, Seminara, Shah, \& Szerszen, 2020)

In a research conducted in The United Kingdom, it surfaced that, the medical fraternity aimed to reduce the face to face consultation for outpatient attendances to $20 \%$, however, it achieved to deliver $87 \%$ of its consultation virtually. The patients gave a satisfaction score of 90/100 and the clinicians rated 78/100 for the same. (Gilbert, Billany, \& Adam R, 2020)

Based on these finds, it has inspired me to conduct a similar study on the Indian consumer perception with respect to the city of Mumbai, which has been one of the worst affected cities in India due to the pandemic. The research gaps I aim to fill are pertaining to the evolving trend of acceptance of Telehealth among the subjects of my study and the satisfaction sought post consuming telehealth services.

\section{RESEARCH OBJECTIVES-}

To study the evolving trend and perception of the consumers towards Telehealth in the age of Covid-19.

\section{RESEARCH METHODOLOGY-}

Research Methodology has primarily been focused around data collection. Primary data will be collected by conducting survey research and qualitative interviews.

Type of Research- Quantitative

Sampling- Random Convenience Sampling, Random Snowball Sampling.

Sample Size- 379 respondents

\section{Questionnaire}

The questions for the study were selected on the basis of research conducted on the same topic pertaining to user perception and satisfaction in different geographical locations across the globe, i.e.- (Mair \& Whitten, 2000)(Becevic, Boren, \& Mutrux, 2015) (Acharya \& Rai, 2016).

A pilot study had been conducted with 50 respondents to gauge the understanding of the questions among the respondents. It was ensured that the respondents understood what the questions meant and were correctly framed and interpreted before rolling out the questionnaire to the other respondents. 


\section{Profile of Respondents}

Age-

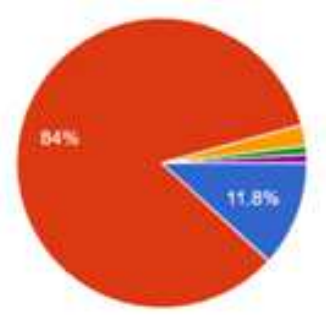

Gender-

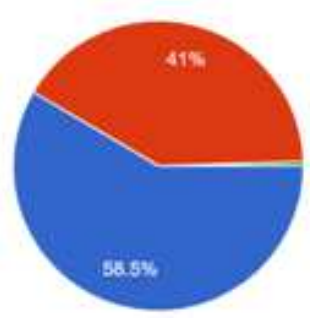

- Maie

- Female

Other

- Preser not to say

\section{Figure 1}

A total of 379 respondents participated in the study, out of which $58 \%$ were male and $41 \%$ were female. A majority $(84 \%)$ of the respondents fall in the age group of 20-30.

\section{Statistical Tools \& Software}

On collecting the responses, the numeric data obtained from the close-ended questions were entered in a spreadsheet for statistical analysis. Statistical tests such as Exploratory Factor Analysis, Mean score analysis were conducted on the data. Simple statistical tests were also conducted on the descriptive questions. The softwares used for the data analysis have been Microsoft Excel 2013 and SPSS version 26.

\section{RESULTS \& FINDINGS}

\section{Factor Analysis}

\section{Reliability}

[Dataset1]

\section{Scale: ALL VARIABLES}

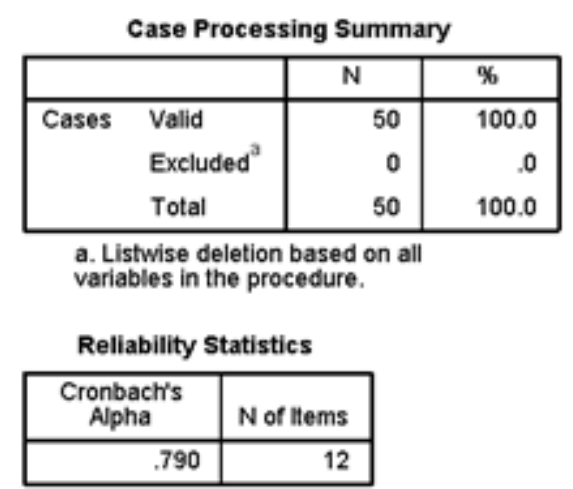

Table 1: KMO and Bartlett's Test

\begin{tabular}{|c|c|c|}
\hline Kaiser-Meyer-Olkin Measure of Sampling Adequacy. & .814 \\
\hline \multirow{3}{*}{ Bartlett's Test of Sphericity } & Approx. Chi-Square & 1395.265 \\
\cline { 2 - 3 } & Df & 66 \\
\cline { 2 - 3 } & Sig. & .000 \\
\hline
\end{tabular}


Table 2

Total Variance Explained

\begin{tabular}{|c|c|c|c|c|}
\hline \multirow[b]{2}{*}{ Component } & \multicolumn{3}{|c|}{ Initial Eigenvalues } & \multirow{2}{*}{$\begin{array}{c}\text { Extraction } \\
\text { Sums of } \\
\text { Squared } \\
\text { Loadings } \\
\text { Total }\end{array}$} \\
\hline & Total & $\%$ of Variance & Cumulative $\%$ & \\
\hline 1 & 4.218 & 35.152 & 35.152 & 4.218 \\
\hline 2 & 1.367 & 11.396 & 46.548 & 1.367 \\
\hline 3 & 1.255 & 10.459 & 57.007 & 1.255 \\
\hline 4 & 1.060 & 8.835 & 65.843 & 1.060 \\
\hline 5 & .761 & 6.345 & 72.188 & \\
\hline 6 & .664 & 5.529 & 77.717 & \\
\hline 7 & .608 & 5.069 & 82.786 & \\
\hline 8 & .577 & 4.806 & 87.592 & \\
\hline 9 & .475 & 3.955 & 91.547 & \\
\hline 10 & .390 & 3.246 & 94.794 & \\
\hline 11 & .368 & 3.064 & 97.857 & \\
\hline 12 & .257 & 2.143 & 100.000 & \\
\hline
\end{tabular}

Scree Plot

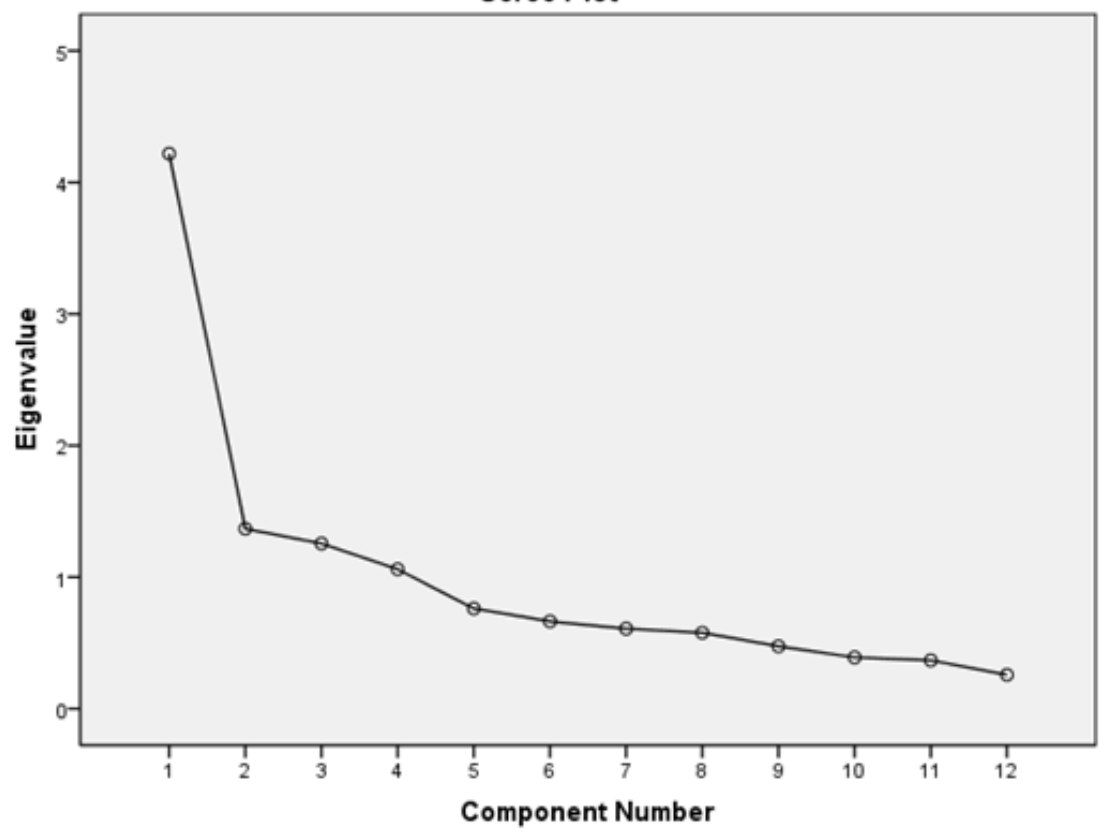

Figure 2 
Table 3

Rotated Component Matrix

\begin{tabular}{|c|c|c|c|c|}
\hline & \multicolumn{4}{|c|}{ Component } \\
\hline & 1 & 2 & 3 & 4 \\
\hline Trust in Dr's online assessment. & .762 & & & \\
\hline Saving time and money & .736 & & & \\
\hline Efficiency from Dr \& his team & .709 & & & \\
\hline Likelihood to recommend & .588 & & & \\
\hline Post Covid-19 boom of telehealth. & & .872 & & \\
\hline Future use of service & & .750 & & \\
\hline Ease in communication with $\mathrm{Dr}$ & & & .729 & \\
\hline Privacy & & & .709 & \\
\hline Patience and attention of $\mathrm{Dr}$ & & & .605 & \\
\hline Comfort with being on Camera & & & & .792 \\
\hline Satisfaction & & & & .655 \\
\hline Lack of physical contact & & & & 612 \\
\hline
\end{tabular}

Extraction Method: Principal Component Analysis.

Rotation Method: Varimax with Kaiser Normalization.

a. Rotation converged in 6 iterations

During the Pilot study the reliability test was conducted which requires a minimum Cronbach's Alpha value of 0.6, and this condition was met by securing a Cronbach's Alpha value of 0.79. The KMO and Bartlett's test requires a minimum score of 0.7 and above to prove that the sample size is adequate. Achieving a score of 0.814 proves that the sample adequacy has been met. 4 of the factors have an Eigenvalue of above 1, and based on the Scree Plot, it is implied 4 factors have been extracted. Lastly, the item landing cut off was set at 0.5 and all the landings were above 0.5 ensuring no duplication.

Based on the Exploratory Factor analysis, we have 4 factors for our study. The four factors that influence the consumer perception towards telehealth in the age of covid-19 are

\section{Efficiency}

Trust and accuracy in Doctor's online assessment, Ability to save time \& money, Efficiency in organising the process and Ability to recommend the service to others contribute to and have been clubbed as Efficiency.

\section{Future Adaption}

Future adaption has been extracted by variables that emphasize on the post Covid-19 boom of telehealth and the likelihood of the respondents using the service again in the future.

\section{Personalisation}

Ease in communicating with the Dr, patience and attention of the doctor while receiving consultation and privacy have been clubbed as a factor labelled Personalisation.

\section{Comfort \& Satisfaction}

Comfort with being on camera with the Doctor, Comfort with the lack of physical contact in a telehealth consultation and overall satisfaction post receiving the service have been clubbed as a factor called Comfort \& Satisfaction. 


\section{Mean Score Analysis}

- The respondents had an average satisfaction score of 3.8/5 for the telehealth services they consumed.

- The respondents had an average score of $4 / 5$, when asked whether telehealth would save them time $\&$ money. (1 being strongly disagree and 5 being strongly agree)

- When asked about Dr-Patient privacy, the respondents gave an average score of $4.2 / 5$, emphasizing on the fact that telehealth would not compromise on their privacy and confidentiality with their Doctor.

- There was an average score of 3.7/5 when asked about the likelihood to use telehealth in the future again. (1 being highly unlikely and 5 being highly likely)

- The respondents gave an average score of 3.9/5 to the likelihood of recommending telehealth to their peers and family. ( 1 being highly unlikely and 5 being highly likely)

\section{DISCUSSIONS}

A total of 379 respondents participated in the study, out of which $58 \%$ were male and $41 \%$ were female. A majority (84\%) of the respondents fall in the age group of 20-30.

On conducting the exploratory factor analysis, we've extracted 4 factors for our study. Let's discuss them in detail.

\section{Efficiency}

The first extracted factor has been labelled as Efficiency. It lays emphasis on the efficiency of the process and how efficiency plays a role in the perception of the consumers towards adapting and accepting telehealth.

In person consultation has been the conventional and comfortable method of visiting a doctor. Telehealth is the new practice that looks to challenge the conventional methods. The adaptation of a new method is led by acceptance among the users, and acceptance of a new method is hugely impacted by its efficiency.

The acceptance of telehealth will be hugely determined by how smoothly the doctor and his team can deliver the service.

A doctor is primarily judged by the patient on his consultation and the accuracy of his diagnosis and treatment. An important aspect of telehealth is the doctors should be able to give the correct diagnosis. This would in-turn build trust among a patient and the doctor. So, from a consumers perspective efficiency in the process will be built by correct consultation and diagnosis, and it is of utmost importance that the doctor's assessments are correct irrespective of the platform, thereby increasing the trust of the patients in the assessments of the doctor and the platform of consultation.

Efficiency from a consumer's perspective is hugely influenced by time and money. Consumers believe a product or a service to be efficient if it can deliver and save time and money at the same time. Telehealth can prove pivotal in saving a consumer's time. The very fact that there isn't the need to drive to a clinic and wait for your turn and rather just login to your computer at the appointed time helps save a lot of time of the patients. Consumers feel that telehealth would reduce the expenses of the doctors as well as there would be a reduced electricity bill and lesser infrastructural expenses for them to say the least, which would in turn reduce consultation fees. The respondents strongly backed this statement, as they gave an average rating of $4 / 5$ on a scale to measure the likelihood of telehealth saving the patients time and money. 
Interestingly $79 \%$ of the respondents believe that telehealth consultation should be charged lesser than in person consultation, in contrary to the remaining $21 \%$ who feel the consultation prices should be the same, irrespective of the medium.

Apart from accuracy in diagnosis, efficiency is also needed in running and curating the entire process. The Dr and his team need to efficiently manage time and must ensure they have the regular resources needed to smoothly carry out the process. Small mismanagement like not scheduling appointments properly will end up in causing delay and wasting the time of the doctor and the patients, thereby hampering the efficiency of the entire process.

Hence, accuracy and trust in Dr's online assessment, the ability of telemedicine to be able to save the consumer's time and money, smooth handling of the process by the Dr and his team will ensure in keeping up the efficiency of the process. Respondents have an average score of 3.9/5 when asked about the likelihood of them recommending their doctor to their peers and family for telehealth consultation based on the efficiency and their experience of the process.

\section{Future Adaption}

Consumer perception is hugely influenced by the future adaption and viability. Consumers do not feel inclined towards changing their current or conventional methods and adapting to new processes if there is no viability for it in the future. Hence, Future adaptability is a huge factor when it comes to consumer perception.

One of the key points under this has been the views of the consumers towards telehealth in the post Coivd-19 era. Respondents gave an average rating of 3.9/5 when asked about the likelihood of a boom in the telehealth industry in the post Covid-19 era. There is a belief that the lockdown forced people to stay indoors and this pushed people to try telehealth consultation to communicate with their doctors for follow up check-ups and for lesser alarming medical fatalities, for the sake of their and the doctor's safety from the Coronavirus. The lockdown has helped the consumers get a feel of the service and there is a positive response in them with respect to using a platform that they have got a feel of and are not completely new to now. Pre-Lockdown, patients didn't bother much to give telehealth a try as they were comfortable with the conventional consultation and reluctant to try something new. But as the lockdown forced them to give telehealth a try, more consumers have gotten a feel of the service, and since they aren't completely alien to it now, it will be considered and be used more often as compared to the pre-covid-19 times. This feeling was also shared with the respondents as they gave a mean score of $3.7 / 5$ when asked about the likelihood of them using telehealth to see their doctor again in the future. On the basis of these studies, future adaptation can be extracted as a pivotal factor in the study analysing the consumer perception.

\section{Personalisation}

Personalisation is pivotal for the success of any product or service. No two patients are the same, and hence shouldn't be treated as one. Doctors must ensure that they understand the patient and what they are trying to imply. The lack of physical contact needs to be made up by better and fluidic communication between the doctor and his patients. The patient must feel comfortable and must be at ease while speaking to the doctor. But this isn't a one way street, the doctor must be equally comfortable and must be able to ask the right questions that would help him diagnose and consult the patient better.

Personalisation will require the doctor to be patient and attentive. Telehealth as a mode of consultation will be new to many doctors just as it will be new to many patients. The doctors must ensure that consultation isn't done in a hurry and they must be patient and give the required time and attention. This helps in making the patient comfortable. Being at 
ease is an important factor when it comes to opening up, and it is up to the doctor to provide a virtual environment where their patients are made to feel comfortable and at ease. This would help and facilitate better communication. Ease in communication will provide a much needed fluidity which will help the doctor analyse the situation better before providing their diagnosis. Another aspect that makes personalisation so important is the privacy. Doctors would have to maintain privacy and abide by patient-doctor confidentiality ethics. Even though there is a change in platform, there is still heavy emphasis and importance given to communication, patience, attention and privacy, and hence can be clubbed as personalisation. Doctors must still maintain the same standard of care, comfort and morals as they do for in-person consultation.

Respondents gave a mean score of $4 / 5$ when asked about the time and attention given by the doctor to them while receiving telehealth consultation, and a mean score of 4.2/5 when asked about patient-doctor confidentiality in the same scenario.

\section{Comfort \& Satisfaction}

The fourth and final factor that has been extracted from our study has been the comfort and satisfaction of the consumers. Telehealth involves the use of telecommunication to deliver medical information. Not always does a doctor get a clear understanding of what the patient is trying to say over a phone call, so it is quite likely that a doctor might need face to face communication with the patient over a video call. It is of utmost importance that a patient is comfortable to be on camera. A patient must be comfortable to be on camera with the doctor and give him the opportunity to assess and diagnose the situation. It is also pivotal that the patient must be comfortable with the lack of physical contact in a telehealth consultation. As ironic as it sounds, patients have to be comfortable being on camera while being okay with the lack of physical contact. Lack of physical contact requires the patients to be more vocal and communicate better, as the doctors would not be able to physically conduct certain preliminary tests. In such scenarios better communication will help ease the process and will make the doctor's job easier with suggesting the further plan of care and medication. It has been observed that patients are comfortable to be on camera with their regular doctor or for a follow up check-up in contrary to a first time visit. Quite understandably so. Visiting a family physician or while going for a follow up visit, the patients know the doctor and the sense of familiarity helps in making them feel at ease. The respondents gave an average rating of 3.7/5 when asked about their comfort levels with respect to being on camera with their doctor and a similar score, $3.7 / 5$ was also given by the respondents to being comfortable with the lack of physical contact with the doctor and ease of communicating with them.

Consumer satisfaction is one of the most important aspects when it comes to consumer perception of any service. The sheer fact that whether a consumer is satisfied or not can decide the fate of a product or a service. When it comes to telehealth the consumers must feel that the doctor has understood their concern and must have faith in the suggested remedy. Satisfaction and faith can often be the first step towards recovery and improvement. It is what gives a sense of positivity and belief to the mind.

It is said that necessity is the mother of invention. Telehealth has existed since a long time now, but the lockdown compelled a lot of people to give telehealth a chance. A lot of people resorted to this service for minor and medium medical needs as to avoid stepping out and risking individual health. On communicating and getting their responses to the questionnaire, $71 \%$ of the people gave a satisfaction score of 4 and above out of 5, and only $2 \%$ people had a satisfaction rating of 2 or below out of 5; which speaks highly of the service and the tremendous potential it holds in the post Covid-19 
era. On these basis, aspects such as being on camera, lack of physical contact and overall satisfaction have been extracted as a factor called, Comfort and Satisfaction.

\section{CONCLUSIONS}

Through this study it has come to my knowledge that the lockdown has compelled the masses to adapt and use telehealth. On collecting their responses to my questionnaire I firmly believe that most of the people have had positive experiences. It is also learnt that telehealth consultation does not aim to substitute in-person consultation, but rather to compliment it. Serious medical conditions and casualties would still require the physical presence and expertise of a doctor. Telehealth is advisable for regular follow up check-ups or minor and mild medical casualties that would not require the physical presence of a doctor. For such cases, telehealth consultation can prove to be very useful in saving time, money and resources for both the doctor and the patient. Our findings in this research have displayed a similar trend as compared to the study on the same subject in other parts of the world. A study on the subject conducted in the United Kingdom also showed high satisfaction score of 90/100 for the consumers post consuming telehealth services (Gilbert, Billany, \& Adam R, 2020). A similar study was conducted (Wijesooriya, Mishra, Brand, \& Rubin, 2020) which also suggested that Telehealth has helped patients receive personalised care from their clinicians, and has also given doctors suffering from mild symptoms to cater to their patients. A study conducted on the user satisfaction with telehealth (Becevic, Boren, \& Mutrux, 2015) has also extracted Efficiency and Future adoption as an important factor drawing similarity to the factors extracted from our study,

The unforeseen pandemic has acted like a catalyst in the spread of telehealth. More people have gotten a feel of the service and this in turn has created a positive perception about the industry. People have been satisfied with their experience and are further willing to practice this even post the lockdown. Nothing is as strong as 'word of mouth', and seeing the number of respondents who have been highly satisfied and who would like to recommend this service to their peers and family brings great potential and boom to this industry.

This research has aimed to study the consumer's perspective towards receiving and participating in telehealth. It has helped understand their perception of the service based on their experiences. This research can be of use and help for further study, research and understanding. Marketing researchers could use this as a platform to understand and dive deeper into the consumer's mind to know what they feel and how the industry could be made more commercially viable from a marketing perspective. Medical professionals could use this to understand the wants and needs of their patients. Understanding what the patients prefer would help them serve better, thereby improving their service and the consumer's experience.

\section{BIBLIOGRAPHY}

1. Acharya, R., \& Rai, J. (2016). Evaluation of patient and doctor perception toward the use of telemedicine in Apollo Tele Health Services, India. JFMPC, 798-803.

2. Allen, A., \& Perednia, D. (1995). Telemedicine Technology and Clinical Applications. JAMA The Journal of the American Medical Association, 483-488.

3. Ateriya, N., Saraf, A., Meshram, V., \& Setia, P. (2018). Telemedicine and virtual consultation: The Indian perspective. NMJI, 31(4), 215-218.

4. Bagchi, S. (2006). Telemedicine in Rural India. PLoS Med. doi:10.1371/journal.pmed.0030082 
5. Bashshur, R. (1997). Critical issues in telemedicine. Telemed. J.

6. Bashshur, R., \& Shannon, G. W. (2009). History of Telemedicine: Evolution, Context, and Transformation. New York: Mary Ann Liebert, Inc.

7. Becevic, M., Boren, S., \& Mutrux, R. (2015). User Satisfaction With Telehealth. The Health Care Manager, 337-349.

8. Bestsennyy, O., Gilbert, G., Harris, A., \& J, R. (2020, May 29). Telehealth: A quarter-trillion-dollar post-COVID-19 reality? Mckinsey \& Company. Chicago, Illinois, USA. Retrieved from https://www.mckinsey.com/industries/healthcare-systems-andservices/our-insights/telehealth-a-quarter-trillion-dollar-post-covid-19-reality

9. Brecht, R. M., Gray, C. L., Peterson, C., \& Youngblood, B. (1997). PhyCor, MedPartners in \$6.98 Billion Deal. The Wall Street Journal.

10. Chellaiyan, V., Nirupama, A., \& Taneja, N. (2019). Telemedicine in India: Where do we stand? JFMPC, 8(6), $1872-1876$.

11. Dick, P., Filler, R., \& Pavan, A. (1999). Participant satisfaction and comfort with multidisciplinary pediatric telemedicine consultations. J Pediatr Surg, 137-141.

12. Escobar, A. (1994). Welcome to Cyberia: Notes on the Anthropology of Cyberculture (Vol. Current Anthropology 35).

13. Ganapathy, K. (2020, April 19). COVID-19 enhances reliance on telemedicine. The Hindu . Tamil Nadu, India. Retrieved from https://www.thehindu.com/news/national/tamil-nadu/covid-19-enhances-reliance-on-telemedicine/article31378946.ece

14. Gilbert, A., Billany, J., \& Adam R, e. a. (2020). Rapid implementation of virtual clinics due to COVID-19: report and early evaluation of a quality improvement initiative. BMJ Open Quality. doi:10.1136/bmjoq-2020-000985

15. Green, B., Pence, T., Kwan, L., \& Rokicki-Parashar, J. (2020). Rapid Deployment of Chiropractic Telehealth at 2 Worksite Health Centers in Response to the COVID-19 Pandemic: Observations from the Field. Journal of Manipulative and Physiological Therapeutics.

16. Ho, K., Karlinsky, H., \& S, J.-S. (2004). Videoconferencing for telehealth: unexpected challenges. BCMJ, 46(6), $285-289$.

17. Hollander, J., \& Carr, B. (2020). Virtually Perfect? Telemedicine for Covid-19. The New England journal of medicine.

18. Ketaren, S. Otniel, et al. "Environmental health aspect in health emergency management (a case study: SinabungVulcanous Eruption)." Int. J. Appl. Nat. Sci. 5 (2016): 47-56.

19. Maese, J., Seminara, D., Shah, Z., \& Szerszen, A. (2020). What a Difference a Disaster Makes:. American Journal of Medical Quality, 1-2.

20. Mair, F., \& Whitten, P. (2000). Systematic review of studies of patient satisfaction with. BMJ, 1517-1520.

21. Medical Council of India. (2020, March 25). Telemedicine Practice Guidelines. Retrieved from https://www.mohfw.gov.in/pdf/Telemedicine.pdf

22. Moeckli, J., Cram, P., Cunningham, C., \& Reisinger, H. (2013). Staff acceptance of a telemedicine intensive care unit program: A qualitative study. Journal of critical care .

23. Nirmala, S. Guptha, and K. Thanuja."Wireless Technology to Monitor Remote Patients-A Survey. "International Journal of Computer Networking, Wireless and Mobile Communications (IJCNWMC) 4.2, Apr 2014, 65-76

24. Roehr, B. (2012). US model for hospital care at home reduces costs and increases patient satisfaction. BMJ. doi:10.1136/bmj.e3997 
25. Sinha, A. (2000). An Overview of Telemedicine: The Virtual Gaze of Health Care in the Next Century. Medical Anthropology Quarterly, 14(3), 291-309.

26. Thaker, D., Monypenny, R., Olver, I., \& Sabesan, S. (2013). Cost savings from a telemedicine model of care in northern Queensland, Australia. Med J Aust, 199(6), 414-417.

27. The Economic Times. (2020, May 23). ET Health World. Retrieved from ET Health World : https://health.economictimes.indiatimes.com/news/industry/telehealth-a-tech-based-weapon-in-the-war-against-thecoronavirus/75894347

28. The Economist. (1997). Healing and the Great Divide. U.S. News \& World Report. The Economist (U.S. edition), 123(14).

29. Wade, V., Karnon, J., \& Elshaug, A. (2010). A systematic review of economic analyses of telehealth services using real time video communication. BMC Health Serv Res, 10, 5,10. doi:https://doi.org/10.1186/1472-6963-10-233

30. Wijesooriya, R., Mishra, V., Brand, P. L., \& Rubin, B. K. (2020). COVID-19 and telehealth, education, and research adaptations. Paediatric Respiratory Reviews, 2-9. doi:https://doi.org/10.1016/j.prrv.2020.06.009

31. World Health Organisation . (2016). Telehealth. Retrieved from World Health Organisation : https://www.who.int/gho/goe/telehealth/en/ 

